\title{
PACING OPPORTUNITIES AT HOME AND SKILL OF CHILDREN WITH POTENTIAL CHANGES IN FUNCTIONAL DEVELOPMENT
}

\author{
Joselici da Silva ${ }^{1}$, Jaqueline da Silva Fronioº, Rayla Amaral Lemos ${ }^{3}$, Luíz Cláudio Ribeiro ${ }^{4}$, \\ Thalita Souza de Aguiar ${ }^{5}$, Daniele Thomé Silva ${ }^{6}$, Marcela Tamiasso Vieira?, Luiz Antônio \\ Tavares Neves ${ }^{8}$
}

\begin{abstract}
Introduction: the multifactorial nature of motor development is reinforced by the combination of biological and environmental risk factors, which intensify the chances of impaired motor development. Objectives: to verify the relationship between functional mobility skills of children with risk factors and motor stimulus opportunities in their home environment. Methods: transversal study conducted with 112 patients aged 18-42 months from follow-up services. Motor stimulus opportunities were evaluated by the Affordance in the Home Environment for Motor Development (AHEMD-SR) and Functional mobility skills by the Pediatric Evaluation Disability Inventory (PEDI). Student t test and multiple linear regression analysis were carried out. Results: predominance of good performance of functional mobility skills and "average level" of environmental stimulus opportunities were observed. There was no significant association between HFM-PEDI and AHEMD-SR. The results showed significant association only between HFM-PEDI and presence of health problems $(p=0.004)$. Children with health problems had lower mean PEDI normative score. Multiple linear regression analysis showed significant result for health problems in the interaction among environment, control variables and HFM-PEDI $(p=0.003)$. Conclusion: there was no association between functional mobility skills of children with risk factors and motor stimulus opportunities in their home environment. On the other hand, children with some health problem showed lower performance in functional mobility skills.
\end{abstract}

ABSTRACT

Key words: child development, activities of daily living, premature, preschool children, risk factors.

\section{INTRODUCTION}

The development process is the result of a set of factors that interact with each other. Among them, the exposure to biological, genetic, psychological, social and environmental factors can be mentioned, which can be modified or boosted ${ }^{1,2}$. Thus, the cumulative effect of multiple risk factors increases the likelihood of impaired motor development and reinforces the multifactorial nature of child development ${ }^{3,4,5,6}$.

Biological factors, such as prematurity, low birth weight, neonatal complications, among others ${ }^{1,7,8}$ directly affect the potential of motor development and consequently are determinants of delays or changes ${ }^{9}$. Studies show that premature infants, underweight, who suffered neonatal complications have important indices of neurodevelopment delay, which affects subsequently on the development of functional skills and independence ${ }^{4,10}$. In this context, adequate care during pregnancy helps to identify and treat maternal conditions and habits that can help to prevent the occurrence of premature births and children with low birth weight ${ }^{11}$.

The first years of a child's life are characterized as a period of important neurological maturation and acquisition of basic motor skills, in which there is optimization of the construction process of motor behaviors that are decisive for the subsequent motor development ${ }^{12,13}$. Thus, the constant transformation and improvement of motor

1 MSc. in Public Health from Universidade Federal de Juiz de Fora (UFJF), Juiz de Fora, MG, Brazil.

$2 \mathrm{PhD}$ in Medical Sciences from the Universidade Estadual de Campinas (UNICAMP) and Professor at the Department of Physical Therapy - School of Medicine, Universidade Federal de Juiz de Fora (UFJF) Juiz de Fora, MG, Brazil.

3 MSc. in Public Health from Universidade Federal de Juiz de Fora (UFJF), Juiz de Fora, MG, Brazil.

$4 \mathrm{PhD}$ in Demography from Universidade Federal de Minas Gerais (UFMG) and Professor at the Department of Statistics, Institute of Mathematical Sciences, Universidade Federal de Juiz de Fora (UFJF) Juiz de Fora, MG, Brazil.

5 Physiotherapist from Universidade Federal de Juiz de Fora (UFJF), Juiz de Fora, MG, Brazil.

6 Physiotherapist from Universidade Federal de Juiz de Fora (UFJF), Juiz de Fora, MG, Brazil.

7 Physiotherapist from Universidade Federal de Juiz de Fora (UFJF), Juiz de Fora, MG, Brazil.

8 PhD in Child and Women's Health at the Oswaldo Cruz Foundation (FIOCRUZ) and Professor at the Maternal Child Department, School of Medicine, Universidade Federal de Juiz de Fora (UFJF), Juiz de Fora, MG, Brazil.

Article based on the dissertation "Opportunities for stimulation at home environment and functional ability of infants and preschool children with risk factors for changes in their development" presented to the Graduate Program - Master course on Public Health, Federal University of Juiz de Fora, 2013.

Corresponding author: joselici@yahoo.com.br

Suggested citation: da Silva J, et al. Pacing opportunities at home and skill of children with potential changes in functional development. Journal of Human Growth and Development. 25(1): 19-26

Manuscript submitted May 08 2014, accepted for publication Oct 122014. 
skills allow the acquisition of functional abilities, independence and greater adaptability to the environment ${ }^{14}$.

Functional abilities are those that enable the execution of daily life tasks of every age insofar as they evolve, will provide independence, autonomy and better environmental exploration. Thus, the environment in which the child lives, plays a decisive role in his life, so that opportunities present in the home environment may favor or not the construction of functional skills necessary to adaptation and environmental exploration ${ }^{15}$.

However there is still little evidence about the impact of environmental, socioeconomic risk factors and health conditions on the functional skills of Brazilian children with biological risk factors. Through this gap, it is necessary to investigate the supply and availability of home environmental stimulus opportunities for motor development of children with risk factors for changes in development, as well as its possible association with its functional skills. Thus, the objective of this study is to verify the relationship between functional mobility skills of children with risk factors and motor stimulus opportunities in their home environment, and corroborate if this relationship is affected by biological and socioeconomic factors

\section{METHODS}

\section{Participants}

This is a transversal study, which analyzed a sample of infants and preschool children with risk factors for developmental disorders residing in the city of Juiz de Fora-MG and registered in the follow up service of the University Hospital at the Federal University of Juiz de Fora and the municipality of Juiz de Fora - MG State, Brazil. . The sites to recruit the participants were chosen for being reference service to the egress risk population of Neonatal Intensive Care Units (NICU).

Inclusion criteria were patients enrolled in these follow-up services aged between 18 and 42 months and with at least one risk factor for abnormal development, such as less than 37 weeks gestational age, low birth weight, mechanical ventilation (MV), perinatal asphyxia, sepsis, periintraventricular hemorrhage, bronchi pulmonary dysplasia (BPD), jaundice, among others ${ }^{16,17}$. The definition of age to participate in the study corresponds to the minimum and maximum age of the instrument used to collect data to evaluate the opportunities present in the home environment (Affordance in the Home Environment for Motor Development- AHEMD-SR ${ }^{13,15}$.

Exclusion criteria were participants living in other municipalities, children with moderate to severe cerebral palsy (GMFCS IV or V) ${ }^{18}$ or malformations and genetic syndromes, since the instrument used in the study investigates opportunities and activities that are not interesting or possible for children with difficulty or inability to locomotion.

Participants were selected through a random sampling, following a predetermined order by lot.
Among the 395 potential participants, 14 (3.5\%)were excluded for living in another city, 13 (3.2\%) for having Cerebral Palsy (CP), Down Syndrome or Myelomeningocele, 08 (2\%) because were out of the study age range at the time of collection and 19 (4.8\%) for refusing to participate. Furthermore, it was not possible to locate 229 (57.9\%) patients through their registered data from the records of services even after 3 attempts of phone contacts at different times and days, and also trying to contacting them through their neighbors and public health services. Thus, the final sample consisted of 112 participants.

\section{Instruments}

The Affordance in the Home Environment for Motor Development (AHEMD-SR) instrument was used to assess the quantity and quality of stimulation in the home environment of children aged between 18 and 42 month ${ }^{15,19}$. The AHEMDSR was developed by the Polytechnic Institute of Viana do Castelo (Portugal) in conjunction with the Motor Development Laboratory at Texas A \& M University (USA) and validated to Brazilian sociocultural conditions. The instrument consists of a total of 67 questions related to the opportunities of the home environment, which are divided into four dimensions: characteristics of child and family, physical space, daily activities and toys, and these are subdivided into five subscales: Outer Space, Inner space, variety, fine motor material and gross motor material.

After completing the questionnaire, data are entered into the calculator (AHEMD Calculator VPbeta1.5.xIs) designed by the AHEMD Project creators. According to the score, calculator provides the total classification of opportunities for stimulation in the home environment into "low", "medium" or "high", and their dimensions into "poor" or "very poor", "good" or "very good"10.

The Pediatric Inventory for dysfunction - PEDI, validated and adapted to the Brazilian reality ${ }^{20}$, is an assessment tool that aims at providing a detailed description of the child's functional performance, his independence and need for adjustments to the environment. The questionnaire is applied through an interview with the caregiver, through which it is possible to evaluate the functional performance and independence in daily activities of children aged between six months to seven and a half years ${ }^{20}$. The test consists of three parts that assess functional skills, caregiver assistance and the adaptations to the environment that the child needs, which are subdivided into three dimensions: selfcare, mobility and social function.

In the present study only the mobility dimension of the first part of the test was used (Functional Skills - assesses transfers and locomotion in inner and outer environment, problem solving, interactive games, jokes, interaction with colleagues and community function), since its purpose was to evaluate the functional capacity of the child mobility and its environment, and this dimension seems to better assess these skills. The final score provides a gross score, which represents the summation of points for each dimension, which 
is transformed through tables contained in the instrument manual into a normative score that allows performance comparison of participants with different ages.

The normative score when between 30 and 70 indicates functional performance within the normal range 20 .

The characterization of socioeconomic level will be carried through the Economic Classification of the Brazilian Association of Research Companies $(A B E P)^{21}$, which seeks to estimate the family's purchasing power. The division into economic classes is defined in levels A through $\mathrm{E}$.

\section{Procedures}

The instruments were applied for three academics of the Physical Therapy School, Federal University of Juiz de Fora (UFJF) and a physical therapist supervisor. The team received prior training before starting the collection, reaching over $90 \%$ intra- and extra-examiner reliability in both tests. Data collection was initiated after approval from the Federal University of Juiz de Fora Research Ethics Committee - UFJF (Opinion No 151. 287) following the draw order definition for participants recruitment.

The interview was previously scheduled with the child's guardian by telephone on the day, time and location appropriate for both. Initially, it was explained the research purpose for the child's responsible, who consenting to participate, had signed the Instrument of Consent. Data on children, families and the Economic Classification Criteria of the Brazilian Association of Research Companies (ABEP) were collected. Later, PEDI was applied and the AHEMD-SR completed by parents. In case of illiterate or semi-illiterate parents, the researcher was responsible for filling the AHEMD based on the information gathered with those responsible through the reading and explanation of the instrument.

\section{Statistical Analysis}

Initially, descriptive analysis was used to characterize the participants' profile. The Student $t$ test was used to verify the association between the dependent variable functional mobility skills (ORDERED), the independent variable opportunities for environmental stimuli (AHEMD-SR), and the control variables (socioeconomic status (SES), maternal education, health problem and attending or not daycare). A multiple linear regression was performed in order to investigate the possible effects of moderator variables on the association between the opportunities for stimulation at home environment and functional mobility skills. The data were stored and analyzed using SPSS version 15.0. In all analyzes was considered á $=0.05$ as significance and trends of differentiation with $p$ values $d^{\prime \prime} 0.1$.

\section{RESULTS}

The study population characteristics are described in Table 1 . The predominant profile of the sample was premature births $(73 \%)$, gestational age between 33 and 36 weeks (44.6\%), and low birth weight (51.8\%). Almost two thirds (74.1\%) of infants or preschool children were not attending kindergarten or school and almost half $(45.5 \%)$ had a diagnosis of any changes that may influence the development. The most frequently reported diagnoses were respiratory disorders (asthma, rhinitis and sinusitis). No children with mild or moderate motor deficit (GMFCS I, II or III) were found. Concerning to sex, there was equivalence between female and male percentage, and the average age of participants was 29.28 months. The age of mothers at the time of data collection ranged between 16 and 47 years, out of these, $47.3 \%$ had completed high school. Families were mostly of

Table 1: Characterization of children's profile with risk factors monitored in follow-up services in the city of Juiz de Fora, MG, Brazil, in 2013

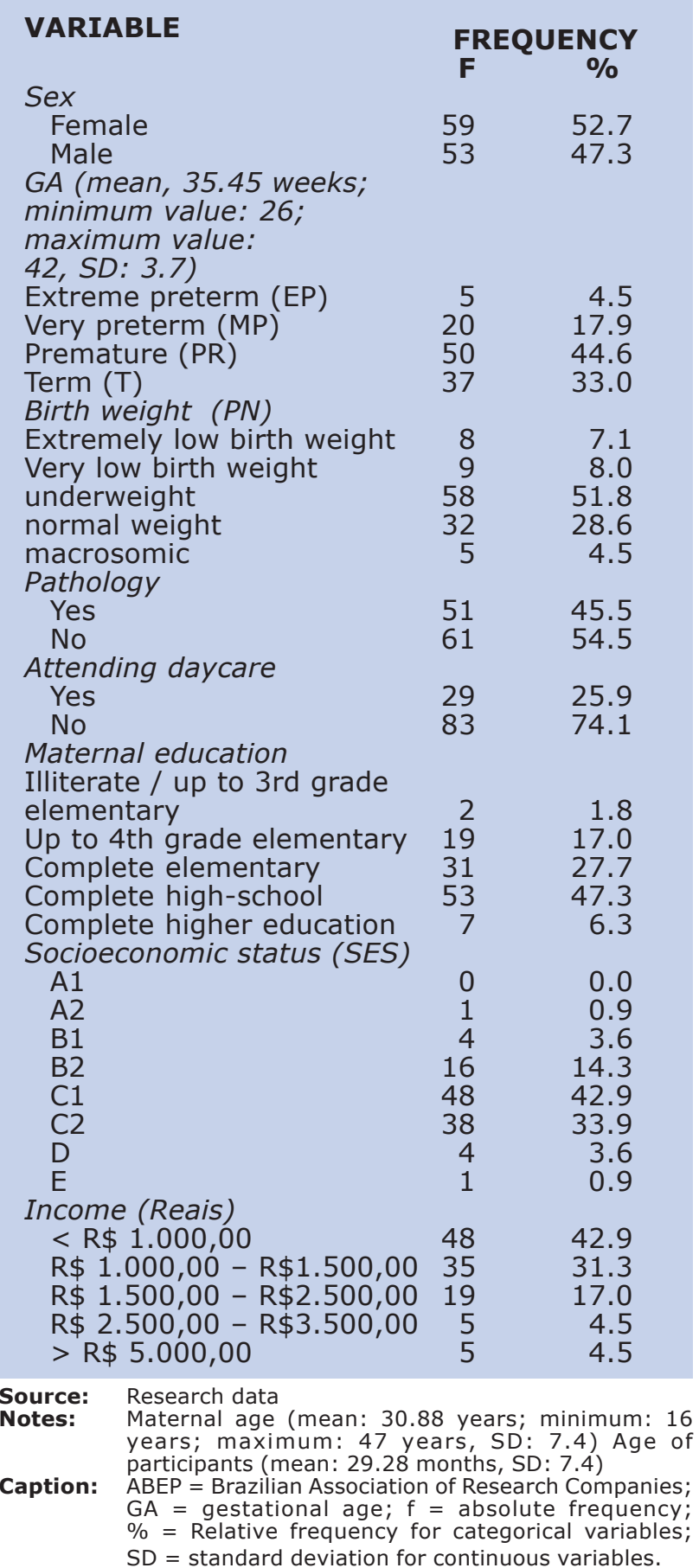


classes $\mathrm{C} 1$ and $\mathrm{C} 2(42.9 \%$ and $33.9 \%)$, with monthly income below $\mathrm{R} \$ 1,000.00$ (42.9\%).

The PEDI's classification of development status and the stimulation in the home environment according to AHEMD-SR are described in Table 2. Regarding the functional mobility skill (HFM), 82.1\% were age-appropriate, while AHEMD-SR's Total classification showed prevalence of "medium level" for the presence of opportunities for home environment stimulation in more than two thirds of respondents ( $74.1 \%)$. In the inner space dimension, most of the participants were classified as "good /

Table 2: Classification of functional ability and opportunities of home stimuli in children with risk factors in the city of Juiz de Fora, MG, Brazil, in 2013

\begin{tabular}{|c|c|c|}
\hline \multirow{2}{*}{ Variables } & \multicolumn{2}{|c|}{ Frequency } \\
\hline & $\mathbf{F}$ & $(\%)$ \\
\hline \multicolumn{3}{|l|}{ PEDI } \\
\hline FMS - Delayed & 17 & 15.2 \\
\hline FMS - Appropriate & 92 & 82.1 \\
\hline FMS - Advanced & 3 & 2.7 \\
\hline \multicolumn{3}{|l|}{ AHEMD-SR Total } \\
\hline Low & 27 & 24.1 \\
\hline Medium & 83 & 74.1 \\
\hline High & 2 & 1.8 \\
\hline \multicolumn{3}{|l|}{ Outer space } \\
\hline Very weak/weak & 59 & 52.7 \\
\hline Good/Very good & 53 & 47.3 \\
\hline \multicolumn{3}{|l|}{ Inner Space } \\
\hline Very weak/weak & 14 & 12.5 \\
\hline Good/Very good & 98 & 87.5 \\
\hline \multicolumn{3}{|l|}{ Variety } \\
\hline Very weak/weak & 29 & 25.9 \\
\hline Good/Very good & 83 & 74.1 \\
\hline \multicolumn{3}{|l|}{ Fine motor skill } \\
\hline Very weak/weak & 105 & 93.8 \\
\hline Good/Very good & 7 & 6.3 \\
\hline \multicolumn{3}{|l|}{ Gross motor skill } \\
\hline Very weak/weak & 105 & 93.8 \\
\hline Good/Very good & 7 & 6.3 \\
\hline
\end{tabular}

Source: Research data

Caption: PEDI = Pediatric Evaluation Disability Inventory; FMS = Functional mobility skills; AHEMD-SR $=$ Affordance in the Home Environment for Motor Development-SR

very good" (87.5\%), while in fine and gross motor skills were "poor / very poor" (93.8\%).

Table 3 shows the t-test results. Despite no statistically significant association having been found between the opportunities for home environment stimuli and functional mobility skills, the PEDI's average normative score remained within the confidence interval of normality (normative score between 30-70) regardless of environmental stimuli present. PEDI normative scores showed greater variability among participants who had the internal space dimension and gross motor skill of AHEM-SR classification, respectively, "good or very good" (mean $42.96 \pm$ SD 14.4) and "weak or very

Table 3: Normative score of functional skill according to the total score and dimensions of the opportunities for home stimuli

$\begin{array}{llll}\text { Variables } & \text { Mean } & \text { SD } & \text { p-value } \\ \text { AHEMD Total } & & & 0.723 \\ \quad \text { Low } & 41.74 & 12.2 & 0.953 \\ \text { Medium or high } & 42.81 & 14.0 & 0.404 \\ \text { Outer space } & 42.48 & 11.0 & 0.929 \\ \quad \text { Very weak/weak } & 42.63 & 16.1 & 0.882 \\ \text { Good/Very good } & 39.70 & 5.3 & 0.905 \\ \text { Very Space } & 42.96 & 14.4 & 12.9 \\ \quad \text { Good/Very good } & 42.35 & 13.9 & 13.8 \\ \text { Variety } & 42.62 & 10.9 & 14.0 \\ \quad \text { Very weak/weak } & 42.50 & 4.4 & \\ \quad \text { Good/Very good } & 43.30 & & \end{array}$

Source: Research data

Caption: PEDI = Pediatric Evaluation Disability Inventory; AHEMD-SR = Affordance in the Home Environment for Motor Development-SR; $\mathrm{p}$-value = statistical significance 
weak "(mean $42.50 \pm$ SD 14.0) opportunities for home environment stimuli.

In addition, an analysis was conducted to verify the existence of association between the PEDI scores and the control variables. The results revealed significant association ( $p=0.004)$ with the variable "health problem", where the PEDI's average normative score was

Table 4: Association between functional skill normative score and the variables presence of pathology, attending daycare, maternal education and socioeconomic status

\begin{tabular}{|c|c|c|c|}
\hline Variables & Mean & SD & p-value \\
\hline Pathology & & & $0.004 *$ \\
\hline Yes & 38.57 & 11.9 & \\
\hline No & 45.88 & 14.5 & \\
\hline Attending daycare & & & 0.797 \\
\hline Yes & 43.12 & 14.6 & \\
\hline No & 42.35 & 10.3 & \\
\hline Maternal education & & & 0.828 \\
\hline Up to complete elementary & 42.25 & 15.9 & \\
\hline High-school / higher education & 42.81 & 11.3 & \\
\hline Socioeconomic status & & & 0.409 \\
\hline $\mathrm{A} 1 / \mathrm{A} 2 / \mathrm{B} 1 / \mathrm{B} 2 / \mathrm{C} 1$ & 41.71 & 13.4 & \\
\hline $\mathrm{C} 2 / \mathrm{D} / \mathrm{E}$ & 41.90 & 13.9 & \\
\hline
\end{tabular}

Source: Research data

Caption: PEDI: = Pediatric Evaluation Disability Inventory; AHEMD-SR = Affordance in the Home Environment for Motor Development-SR; $\mathrm{p}$-value $=$ statistical significance; ${ }^{*}$ significant $\mathrm{p}$ value

lower among participants who had a health problem (Table 4).

The variables SES, maternal education, presence of a health problem and attending or not daycare were included in the multiple linear regression model to check their effect on the association between PEDI and the AHEMD. Results are shown in Table 5. The first model shows that this association is negative, but close to 0 , indicating that this association is not significant $(p=0.416)$. In the other models, the association between the PEDI and the AHEMD-SR Total, when controlled by the variables "maternal education", "socioeconomic status" and "attending a daycare", remains weak and not significant, showing virtually no change on PEDI average compared to Total AHEMD-SR. However, when controlling by AHEMD (model 5), keeping the environment constant, the fact of having health problems reduces the PEDI's normative average score in almost eight points, with highly significant value ( $p=0.003)$, i.e. if the child has some health problem, regardless of the environment he lives, and

Table 5: Multiple Linear Regression - Models according to the moderating variables: presence of pathology, attending day care, maternal education and socioeconomic status in the city of Juiz de Fora, MG, Brazil, in 2013

$\begin{array}{lccc}\text { Models } & \text { R2 } & \text { B } & \text { p-value } \\ \text { Model 1AHEMD } & 0.006 & -0.478 & 0.416 \\ \text { Model 2AHEMD } & 0.088 & -0.609 & 0.298 \\ \text { Socioeconomic status } & & 1.771 & 0.500 \\ \text { Model 3AHEMD } & 0.008 & -0.54 & 0.375 \\ \quad \text { Education } & & 1.139 & 0.671 \\ \text { Model 4AHEMD } & 0.007 & -0.485 & 0.412 \\ \text { Creche } & & 0.865 & 0.771 \\ \text { Model 5AHEMD } & 0.084 & -0.687 & 0.230 \\ \text { Pathology } & & -7.679 & 0.003^{*}\end{array}$

Source: Research data

Caption: PEDI = Pediatric Evaluation Disability Inventory; AHEMD-SR = Affordance in the Home Environment for Motor Development-SR; SES = socioeconomic status; R2 = coefficient of determination; $\mathrm{B}=$ regression coefficient; $\mathrm{p}$-value $=$ statistical significance. $*$ Significant $\mathrm{p}$-value.

will have a significant reduction in the PEDI's normative average of functional skills.

\section{DISCUSSION}

This study began with the assumption that the development of functional mobility skills of children arises from the interaction of the individual with the environment. Thus, we sought to verify the association between stimuli opportunities at home environment and functional mobility skills, and whether it is affected by other factors.
The high prevalence of prematurity and low birth weight in the present study are coming from the sample characteristics, since the population was composed only of children followed in services that provide specialized care to newborns (NB) at risk. This high percentage is a concern, since we know that they are important parameters of morbidity and children mortality in the medium and long term $^{9,11,13,22}$.

Contrary to what was expected, no statistically significant association was found 
between the two variables studied. However, it was observed that more than two thirds of home environments surveyed had medium or high level of stimulation in AHEMD-Total and good or very good opportunities in the dimensions of variety (if the child plays with other children, if choose their toys, if games are stimulated by parents, type of clothing to play, and the time it remains in certain environments) and inner space (presence of apparatuses, internal surfaces and internal space for existing games at home). Opportunities for home environment stimuli are the main catalysts of learning to many children, for being the location where they spend most of the time and allow the experience of different sensorimotor experiences ${ }^{23,24}$. Thus, it seems that participants had favorable conditions for development of functional mobility skills, which reflected in their performance, which remained within the normal range (PEDI normative score).

Although no significant association was found between the stimuli opportunities at home environment and functional mobility skills in the gross motor skills dimension (educational toys, puzzles, friction toys, games and educational materials), the mean PEDI normative scores indicated higher variability among those with weak or very weak chances in this dimension, indicating very different results, among them, low performance. According to the literature, as the child explores toys and games, there are changes in their motor repertoire, which in the early years of life is more strongly influenced by factors such as the variety and quantity and quality of toys ${ }^{13}$. According to Macarini and Vieira ${ }^{25}$, access to different types of toys during infancy provides various social and cognitive developments. Thus, the greater variability of the PEDI normative score, among those who had low levels of stimulation in the gross motor dimension, seems to indicate that the unfavorable conditions in the environment impact on functional mobility skills. Thus, it is emphasized the importance of professionals trained to provide assistance and guidance for the acquisition of materials and their proper use to stimulate children's development ${ }^{26}$.

When analyzing the effect of socioeconomic status, maternal education, health problem and attending daycare on the outcome, it was found that the PEDI's mean normative score was lower among participants who had "health problem" (among the most cited, asthma), which is a significant association. According to Mello, Dutra and Lopes $^{23}$, respiratory disorders are common in premature infants and are important factor for mortality and morbidity in childhood, accounting for recurrent hospitalizations in the first years of life. It is common to observe that most of parents, in order to avoid the disease exacerbation, have excess care, leading to a sort of limitation on motor experiences that can impair the process of developing and refining the functional abilities ${ }^{27}$.
Thus, the presence of health problem may have limited the performance of functional abilities compared means of normative scores.

Considering the effect of moderating variables (NSE), maternal education, health problem and attending daycare) in the association between the independent and the dependent variable, the findings showed that, when controlled by the environment, the presence of health problem exerts statistically significant influence on performance of PEDI functional skills, revealing lower normative score on these skills; i.e. the presence of health problem heavily impacts on the outcome resulting from the environment and individual interaction.

According to the concept of resilience, where a catalyst modification occurs of an individual's response to a hazardous situation, the context of psychosocial support in the family environment of the children evaluated in this study may have worked to turn their potential, minimizing adverse biological risk factors and contributing to satisfactory results of their development ${ }^{28}$. Thus, it seems that despite the increased predisposition to present neuromotor changes, children with risk factors eventually develop strategies that allow them to perform functional activities within normal limits.

One limitation of this study is its crosssectional nature, which provides anecdotal evidence of both functional skills, as opportunities to stimuli present in the home environment. Longitudinal follow-up of children with risk factors for development is crucial, since there is a big change of motor skills in first years of life. Another limitation refers to the difference among profiles of the followup services users. The service with the highest number of users and, consequently, contributed to a greater portion of the sample, consisted of infants of medium and low risk, which may have attenuated the findings related to the outcome.

It was concluded that was no association between the opportunities at home environment and functional mobility skills of infants and preschool children with risk factors. When considering the effects of other variables on the outcome, the presence of a health problem led to significantly lower performance on functional skills. The presence of a health problem on the functional skills heavily impacts on the outcome resulting from the environment and individual interaction. Giving these findings, it is expected to contribute to increase awareness of stakeholders (managers, professionals in the health service, community), in order to create public policies to provide adequate support for populations in vulnerable situations.

\section{ACKNOWLEDGEMENTS}

The University Hospital at the Universidade Federal de Juiz de Fora and the Municipality of Juiz de Fora - MG for providing logistical support for this research. 


\section{REFERENCES}

1. Mancini MC, Megale L, Brandão MB, Melo APP, Sampaio RF. Efeito moderador do risco social na relação entre risco biológico e desempenho funcional infantil. Rev. bras. saúde matern. infant. 2004; 4:25-34. doi: 10.1590/S151938292004000100003

2. Pilz EML, Schermann LB. Determinantes biológicos e ambientais no desenvolvimento neuropsicomotor em uma amostra de crianças de Canoas/RS. Ciênc Saúde Coletiva. 2007; 12(1):181-90. Doi: 10.1590/S1413- 81232007 000100021

3. Halpern R, Giugliani ERJ, Victora CG, Barros FC, Horta BL. Fatores de risco para suspeita de atraso no desenvolvimento neuropsicomotor aos 12 meses de vida. Rev. chil. pediatr. 2002; 73:529-39. doi: 10.4067/S0370-41062002000 500016

4. Lemos RA, Frônio JS, Ribeiro LC, Demarchi RS, Silva J, Neves LAT. Functional performance according to gestational age and birth weight of preschool children born premature or with low weight. J Hum Growth Dev. 2012; 22(1):17-26.

5. Cunha RDS, Lamy Filho F, Silva AAM, Lamy ZC. The predictive value of neonatal brain ultrasound in premature babies for impaired neurodevelopment with a corrected age of 12 months. J Hum Growth Dev. 2010; 20(3): 699-710.

6. Cardoso AA, Magalhães LC, Barbosa VM. Psychomotor development of preterm and full term children at school-age. J Hum Growth Dev. 2011; 21(2): 210-9.

7. Halpern R, Figueiras ACM. Influências ambientais na saúde mental da criança. J Pediatr. 2004; 80(2):104-10. Doi: 10.1590/ S0021-75572004000300013

8. Formiga CKMR, Nonato JCR, Amaral LEF, Fagundes RR, Linhares MBM. Comparison of the motor development in preterm infants from two brazilian regional samples. J Hum Growth Dev. 2013; 23(3): 352-7.

9. Rodrigues OMPR, Bolsoni-Silva AT. Effects of the prematurity on the development of lactentes. J Hum Growth Dev. 2011; 21(1):111-21.

10. Khan NZ, Muslima H, Parveen M, Bhattacharya M, Begum N, Chowdhury S, et al. Neurodevelopmental outcomes of pretrm infants in Bangladesh. Pediatrics. 2006 Jul; 118(1):2809. Doi; $10.1542 /$ peds.2005-2014

11. Maia RRP, Souza JMP. Factors associated with the low birth weight in municipality in northern Brazil. Rev Bras Crescimento Desenvolv Hum. 2010; 20(3):735-44.

12. Isayama HF, Gallardo JSP. Desenvolvimento motor: análise dos estudos brasileiros sobre habilidades motoras fundamentais. Rev Educ Fis. 1998; 9(1): 75-82. Doi: 10.4025/ reveducfisv9n1p75-82

13. Nobre FDA, Carvalho AEV, Martinez FE, Linhares MBM. Estudo longitudinal do desenvolvimento de crianças nascidas pré-termo no primeiro ano pós-natal. Psicol Reflex Crit. 2009; 22(3): 362-9.Doi: 10.1590/S0102-7972200900030 0006

14. Flehmig I. Texto e atlas do desenvolvimento normal e seus desvios no lactente: diagnóstico e tratamento precoce do nascimento até o $18^{\circ}$ mês. São Paulo: Atheneu; 2005.
15. Rodrigues LP, Gabbard C. Avaliação das oportunidades de estimulação motora presentes na casa familiar: projecto affordances in the home environment for motor development. In: Barreiros J, Cordovil R, Carvalheira S. Desenvolvimento motor da criança. Lisboa: Ed. FMH; 2007. p. 51-60.

16. Frônio JS, Neves LAT, Ferraz ST, Demarchi RS, Vargas ALA. Análise da evasão em serviço de follow-up de recém-nascidos de alto risco. HU Rev. 2009; 35(3):219-26.

17. Lemos RA, Frônio JS, Neves LAT, Ribeiro LC. Estudo da prevalência de morbidades e complicações neonatais segundo o peso ao nascimento e a idade gestacional em lactentes de um serviço de follow-up. Rev APS. 2010; 13(3): 277-90.

18. Palisano R, Rosenbaum $P$, Bartlett D, Livingston $M$. Content validity of the expanded and revised Gross Motor Function Classification System. Dev Med Child Neurol. 2008; 50(10):744-50.Doi: 10.1111/j.1469-8749.2008.03089.x

19. Rodrigues LP, Gabbard C. O AHEMD. Instrumento para avaliação das oportunidades de estimulação motora de crianças entre os 18 e os 42 meses de idade. In: Actas do II Congresso Internacional de Aprendizagem na Educação de Infância. 15-17 set. 2007; Maia. p. 51-59.

20. Mancini MC. Inventário de avaliação pediátrica de incapacidade (PEDI): manual da versão brasileira adaptada. Belo Horizonte: Editora UFMG, 2005; 184 p.

21. Associação Brasileira de Empresas de Pesquisa. Critério de classificação econômica Brasil. 2012. c2010. [citado em 2012 abr. 20]. Available from: http://www.abep.org/novo/ Content.aspx?ContentID $=301$

22. Santos DCC, Campos D, Gonçalves VMG, Mello BBA, Campos TM, Gagliardo HGRG. Influência do baixo peso ao nascer sobre o desempenho motor de lactentes a termo no primeiro semestre de vida. Rev Bras Fisioter. 2004; 8(3): 261-6.

23. Mello RR, Dutra MVP, Lopes JMA. Morbidade respiratória no primeiro ano de vida de prematuros egressos de uma unidade pública de tratamento intensivo neonatal. J Pediatr. 2004; 80(6): 503-10. Doi: 10.1590/S0021-7557200 4000800013

24. Torquato JA, Paes JB, Bento MCC, Saikai GMPN, Souto JN, Lima EAM, et al. Prevalence of neuropsychomotor development delay in preschool children. J Hum Growth Dev. 2011; 21(2): 259-68.Doi: 10.1590/S0104-12822011 000200009

25. Macarini SM, Vieira ML. Schoolchildren's play behavior in the toy library. J Hum Growth Dev. 2006; 16(1): 49-60. Doi: 10.1590/S0104-128 22006000100006

26. Alves RCP, Veríssimo Maria DLÓR. Day-care center caregivers and their conflict between giving care and teaching. J Hum Growth Dev. 2007; 17(1): 13-25. Doi: 10.1590/S0104-128 22007000100003

27. Cabral AL, Teixeira LR. Vencendo a asma: uma abordagem multidisciplinar. São Paulo: Bevilacqua; 1994; 96 p.

28. Moraes MCL, Rabinovich EP. Resilience: an introductory discussion. J Hum Growth Dev. 1996; 6(1/2): 10-3. 


\section{RESUMO}

Introdução: a característica multifatorial do desenvolvimento motor é reforçada pela combinação de fatores de risco biológicos e ambientais, que aumentam a probabilidade de comprometimento do desenvolvimento motor. Objetivos: este estudo verificou a associação entre habilidade funcional de mobilidade e oportunidade de estímulos domiciliares de crianças com fatores de risco, e se esta é afetada por fatores biológicos e socioeconômicos. Método: foram avaliadas 112 crianças, na faixa etária de 18 a 42 meses, acompanhadas em serviços de follow-up. Para avaliar as oportunidades domiciliares foi utilizado o Affordance in the Home Environment for Motor Development (AHEMD$S R$ ), e para a habilidade funcional o Inventário de Avaliação Pediátrica de Disfunção (PEDI). A análise estatística foi realizada através do Teste $t$ de Student e análise de regressão linear múltipla. Resultados: houve o predomínio de desempenho "adequado" para as habilidades funcionais, e de "nível médio" para as oportunidades de estímulos domiciliares. No entanto, a associação destas não foi significativa. Encontrou-se significância ( $p=0,004)$ entre as habilidades funcionais e a presença de "problema de saúde". Participantes que apresentavam problema de saúde tiveram menor média no escore normativo do PEDI nessa dimensão. Na análise de regressão linear múltipla a variável problema de saúde apresentou associação $(p=0,003)$, quando considerada a interação entre o ambiente, as variáveis de controle e o desfecho. Conclusão: não houve associação entre as oportunidades domiciliares e a habilidade funcional de mobilidade. No entanto, a presença de "problema de saúde" levou a desempenhos significativamente inferiores nas habilidades funcionais.

Palavras-chave: desenvolvimento infantil, atividade de vida diária, prematuro, pré-escolar, fatores de risco. 